\title{
Activation of PKCe-ALDH2 Axis Prevents 4-HNE-Induced Pain in Mice
}

\author{
Bárbara B. Martins ${ }^{1}$, Natália G. Hösch ${ }^{1}$, Queren A. Alcantara ${ }^{1}$, Grant R. Budas ${ }^{2,3}$, Che-Hong Chen ${ }^{3}$, \\ Daria Mochly-Rosen ${ }^{3}\left(\mathbb{D}\right.$, Julio C. B. Ferreira ${ }^{4}(\mathbb{D})$ and Vanessa O. Zambelli $1, * \mathbb{C}$
}

1 Laboratory of Pain and Signaling, Butantan Institute, São Paulo 05503-900, SP, Brazil; barbara.martins@esib.butantan.gov.br (B.B.M.); natalia.hosh@esib.butantan.gov.br (N.G.H.); queren.alcantara@esib.butantan.gov.br (Q.A.A.)

2 Gilead Sciences Inc., Foster City, CA 94404, USA; grantbudas@gmail.com

3 Department of Chemical and Systems Biology, School of Medicine, Stanford University, Stanford, CA 94305, USA; chehong@stanford.edu (C.-H.C.); mochly@stanford.edu (D.M.-R.)

4 Department of Anatomy, Institute of Biomedical Sciences, University of Sao Paulo, Sao Paulo 05508-090, SP, Brazil; jcesarbf@usp.br

* Correspondence: vanessa.zambelli@butantan.gov.br; Tel.: +55-11-2627-9765

check for

updates

Citation: Martins, B.B.; Hösch, N.G.; Alcantara, Q.A.; Budas, G.R.; Chen, C.-H.; Mochly-Rosen, D.; Ferreira, J.C.B.; Zambelli, V.O. Activation of PKC $\varepsilon-A L D H 2$ Axis Prevents 4-HNE-Induced Pain in Mice. Biomolecules 2021, 11, 1798. https:// doi.org/10.3390/biom11121798

Academic Editor:

Michael Breitenbach

Received: 25 October 2021

Accepted: 26 November 2021

Published: 30 November 2021

Publisher's Note: MDPI stays neutral with regard to jurisdictional claims in published maps and institutional affiliations.

Copyright: (c) 2021 by the authors. Licensee MDPI, Basel, Switzerland. This article is an open access article distributed under the terms and conditions of the Creative Commons Attribution (CC BY) license (https:/ / creativecommons.org/licenses/by/ $4.0 /)$.

\begin{abstract}
Protein kinase $\mathrm{C} \varepsilon(\mathrm{PKC} \varepsilon)$ is highly expressed in nociceptor neurons and its activation has been reported as pro-nociceptive. Intriguingly, we previously demonstrated that activation of the mitochondrial PKC $\varepsilon$ substrate aldehyde dehydrogenase-2 (ALDH2) results in anti-nociceptive effects. ALDH2 is a major enzyme responsible for the clearance of 4-hydroxy-2-nonenal (4-HNE), an oxidative stress byproduct accumulated in inflammatory conditions and sufficient to induce pain hypersensitivity in rodents. Here we determined the contribution of the PKCE-ALDH2 axis during 4-HNE-induced mechanical hypersensitivity. Using knockout mice, we demonstrated that PKC $\varepsilon$ is essential for the nociception recovery during 4-HNE-induced hypersensitivity. We also found that ALDH2 deficient knockin mice display increased 4-HNE-induced nociceptive behavior. As proof of concept, the use of a selective peptide activator of $\mathrm{PKC} \varepsilon$ ( $\Psi$ EHSP90), which favors PKC $\varepsilon$ translocation to mitochondria and activation of PKC $\varepsilon$-ALDH2 axis, was sufficient to block 4-HNE-induced hypersensitivity in WT, but not in ALDH2-deficient mice. Similarly, $\Psi_{\varepsilon} H S P 90$ administration prevented mechanical hypersensitivity induced by endogenous production of 4-HNE after carrageenan injection. These findings provide evidence that selective activation of mitochondrial PKC $\varepsilon$-ALDH2 axis is important to mitigate aldehyde-mediated pain in rodents, suggesting that $\Psi \varepsilon$ HSP90 and small molecules that mimic it may be a potential treatment for patients with pain.
\end{abstract}

Keywords: oxidative stress; neuroprotection; protein kinase; neurodegeneration; hyperalgesia

\section{Introduction}

Pain is a common and disabling complication of inflammatory and neuropathic condition that affects over 1 billion people worldwide [1]. Its related costs increase annually, reaching around US\$ 620 billion/year in the United States alone [2]. The treatment of pain involves the use of therapies that mainly cause symptom relief and are limited by their low efficacy and/or numerous adverse effects. In this scenario, a major coordinated effort towards identification and validation of promising targets affecting pain is critical for further screening and development of more effective and safe interventions.

Protein kinase $\mathrm{C} \varepsilon(\mathrm{PKC} \varepsilon)$ is a serine and threonine kinase that is highly expressed in sensory neurons and when activated it translocates to multiple intracellular sites [3]. PKC $\varepsilon$ activation contributes to hypernociception by increasing the membrane ionic current [4-6]. Other studies demonstrated that the PKC $\varepsilon$ antagonist $(\varepsilon V 1-2)$ induces analgesia in multiple pre-clinical models of inflammatory and neuropathic pain [7,8]. However, despite promising preclinical results, clinical trials for acute severe postoperative pain and chronic 
postherpetic neuralgia failed to show a beneficial effect of $\varepsilon V 1-2$ as an analgesic [7]. These negative findings can be explained by the fact that, regardless of its upstream signaling, the same protein kinase can activate different signaling pathways simultaneously (both essential and detrimental) and therefore affect the effectiveness and safety of PKC inhibitors in the long-term. Under this scenario, $\mathrm{PKC} \varepsilon$ modulators that selectively favors only essentialkinase substrate interaction or inhibits detrimental-kinase substrate interaction might have better efficacy to treat pain.

Emerging evidence suggests that $\mathrm{PKC} \varepsilon$ promotes cell survival by regulating mitochondrial function and signaling. In this regard, we previously described mitochondrial aldehyde dehydrogenase 2 (ALDH2) as one of the PKC $\varepsilon$ substrate, whose activity inversely correlates with hypersensitivity in mice [9]. ALDH2 plays a critical role in metabolizing reactive aldehydes, accumulating during ethanol consumption (i.e., acetaldehyde) and oxidative stress (i.e., 4-hydroxy-2-nonenal, 4-HNE), and it regulates pain-like behavior in multiple models in rodents [10]. Moreover, knock-in ALDH2*2 mice with decreased ALDH2 activity display exacerbated 4-HNE accumulation and pain-like behaviors [9,10]. However, the ALDH2 contribution to aldehydes-induced pain is still unknown.

4 - $\mathrm{HNE}$ is an endogenous $\alpha, \beta$-unsaturated aldehyde generated during oxidative stress, mainly through lipid peroxidation in the mitochondria. Increased 4-HNE adducts in the injured site positively correlates with pain [11]. We previously demonstrated that accumulation of 4-HNE plays a major role in the establishment and progression of pain [9]. Elevated 4-HNE levels were also found in carrageenan-induced inflammation [9], endometriosis [12], spinal cord injury (SCI) [13], experimental autoimmune encephalomyelitis (EAE) [14] and migraine [15]. Mechanistically, 4-HNE can form protein adducts with cysteine, histidine, and lysine residues in proteins via Michael addition; therefore, causing inhibition of protein function and generating pain [16]. For example, 4-HNE targets a transient receptor potential ankyrin 1 (TRPA1), which is highly expressed in sensory nerve fibers and drives pain signaling [17].

Considering the negative effects of 4-HNE accumulation in inflammation and pain, it is expected that increasing 4-HNE clearance through selective activation of PKC $\varepsilon$-ALDH2 axis will positively affect pain outcome. Therefore, using gain and loss of function strategies, we set out to determine the role of PKCE-ALDH2 axis in 4-HNE-induced nociception in mice. We also tested here the possibility that selective pharmacological activation of mitochondrial PKCE-ALDH2 axis counteracts aldehydic load and improves pain-related behaviors triggered by 4 -HNE.

\section{Materials and Methods}

\subsection{Animals}

Experiments were approved by the Ethics Committee on the Use of Experimental Animals at the Butantan Institute (São Paulo, Brazil) and were performed according to the Committee for Research and Ethical Issues of the International Association for the Study of Pain (IASP). In this study we used male mice weighing 20-22 g. The following strains were used: wild-type mice C57BL/6 mice; heterozygous for PKC $\varepsilon\left(\mathrm{PKC}^{+/-}\right)$as previously described [18]; transgenic mice carrying the Asian ALDH2*2 alleles that carry the E487K mutation in the ALDH2 enzyme [9]. They were housed in an appropriate room, with water and food ad libitum with soundproofing, controlled temperature $\left(22 \pm 1^{\circ} \mathrm{C}\right)$, and light-dark cycle $(12 / 12 \mathrm{~h})$.

\subsection{Reagents}

4-Hydroxy-2-nonenal (4-HNE, Sigma, St. Louis, MO, USA), HC-030031 (TRPA1 antagonist, I-TRPA1, Sigma, Barueri, SP, Brazil), Alda-1 (Acme Chemical, Mountain View, CA, USA), Indomethacin (Sigma, St. Louis, MO, USA), TAT (American Peptide Co., Sunnyvale, CA, USA), $\varepsilon$ V1-2 (American Peptide Co.), $\Psi \varepsilon$ Rack (Ontores Peptide, Hangzhou, China), $\Psi_{\varepsilon H S P 90}$ (Ontores Peptide). 


\subsection{Drug Administration}

4-HNE was administered on the plantar surface in different doses (15-120 nmol per paw in $20 \mu \mathrm{L}$ ) or its vehicle (1 nM HCL in saline) [16]. I-TRPA1 (HC 030031; $300 \mathrm{nmol}$ in $20 \mu \mathrm{L}$ ) or its vehicle ( $10 \%$ DMSO, $5 \%$ Tween 80 and $85 \%$ saline) was administered on the plantar surface $[19,20]$. Alda-1 was administered subcutaneously $(10 \mathrm{mg} / \mathrm{kg})$ and DMSO and PEG (1:1) were its vehicle [9]. Indomethacin was administered intraperitoneally $(10 \mathrm{mg} / \mathrm{kg})$ and $5 \%$ sodium bicarbonate in PBS was its vehicle [21]. All vehicles described above are represented as control. For the peptides, the control group was the TAT (YGRKKRRQRRR) carrier administered via intraplantar (1 $\mu \mathrm{g}$ in $20 \mu \mathrm{L}$ of saline). $\varepsilon \mathrm{V} 1-2$ (EAVSLKPT) was administered via intraplantar $(1 \mu \mathrm{g}$ in $20 \mu \mathrm{L}$ of saline) $30 \mathrm{~min}$ before 4-HNE and intrathecal (1.35 $\mu \mathrm{g}$ in $10 \mu \mathrm{L}$ of saline) $15 \mathrm{~min}$ before 4-HNE [22-24]. $\Psi \varepsilon$ Rack (HDAPIGY) was administered via intraplantar ( $1 \mu \mathrm{g}$ in $20 \mu \mathrm{L}$ of saline) [6]. $\psi \varepsilon \mathrm{HSP} 90$ (PKDNEER; $1 \mu \mathrm{g}$ in $20 \mu \mathrm{L}$ of saline) was administered via intraplantar [25]. All peptides were synthesized at Ontores. At displayed purity of $95-99 \%$.

\subsection{Behavioral Testing}

In vivo behavioral testing was blindly performed between 7:00 AM and 1:00 PM in an isolated, temperature-, and light-controlled room. Animals were placed on a mesh floor inside a red acrylic box individually, suspended approximately $30 \mathrm{~cm}$ from the bench, allowing access to the paws. Mice were habituated to the testing apparatus for $30 \mathrm{~min}$ on the day before and the day of the test. The filament was inserted below the mesh floor and onto the plantar skin until the filament just bent. The method used was "up and down" [26]. Thus, a von Frey 9-filament logarithmic series (Aesthesiometer SemmerWeinstein monofilaments, Stoelting Co., Wood Dale, IL, USA) was employed. This method uses stimulus oscillation around the response threshold to determine the median 50\% threshold of the response. The tests started with the $0.6 \mathrm{~g}$ filament. The von Frey filaments were applied six times and the paw removal or not was recorded.

\subsection{Western Blot}

The samples were homogenized in a lysis buffer containing Hepes-NaOH $(1 \mathrm{M}$, PH 7.9), $\mathrm{NaCl}(1.54 \mathrm{M})$, EGTA (200 mM), Triton-X $100(1 \%)$, and protease and phosphatase inhibitors (1:300). Polyacrylamide gel electrophoresis (SDS-PAGE $10 \%$ or $8 \%$ ) was used in a mini gel device (Mini-Protean, Biorad, Santo Amaro, SP, Brazil). After separation by electrophoresis, the proteins were transferred to nitrocellulose membranes (BioRad). The membranes were blocked in TBST (20 mM Tris-HCL, $150 \mathrm{mM} \mathrm{NaCl}$, and $0.1 \%$ Tween 20) containing 5\% BSA for $2 \mathrm{~h}$, followed by incubation with primary antibody against HNE reduced Michael Adducts (1:1000, Millipore, Burlington, MA, USA), ALDH2 (1:500; Abcam, Waltham, MA, USA) or PKC $\varepsilon$ (1:500; Santa Cruz Biotechnology, Dallas, TX, USA) overnight, at $4{ }^{\circ} \mathrm{C}$. Subsequently, the membranes were then incubated, for $2 \mathrm{~h}$ at room temperature, in the appropriate peroxidase-conjugated secondary antibody (1:5000; anti-rabbit IgG or antigoat IgG, Sigma, USA) and developed using enhanced chemiluminescence. Quantification analysis was performed using the UVITEC software (UVITEC Cambridge, Cambridge, UK). Densitometry data were normalized to GAPDH (1:5000; Abcam) and represented as $\%$.

\subsection{Statistical Analysis}

The statistical analysis was generated using the GraphPad Prism 8 program (GraphPad Software Inc., San Diego, CA, USA). Data are expressed as mean \pm SEM. Statistical evaluation of the data was conducted using two-way analysis of variance (ANOVA), followed by Tukey's post hoc test. Statistical $t$-student analysis was performed to analyze Figure 2B,F,H. The significance index considered was $p<0.05$. 


\section{Results \\ 3.1. Disruption of PKCE-ALDH2 Axis Contributes to 4-HNE-Induced Mechanical Hypersensitivity}

Reactive oxygen species-induced peroxidation of polyunsaturated fatty acids produces 4-HNE, which contributes to pain-like behavior in rodents [27]. To characterize the direct effect of 4-HNE on the mechanical nociceptive threshold, we administered 4-HNE in different doses (15-120 nmol/paw) (Figure 1A). Our results showed that the doses of 15 and $30 \mathrm{nmol} /$ paw does not affect the mechanical threshold. However, 60 and $120 \mathrm{nmol} / \mathrm{paw}$ of 4-HNE induce mechanical hypersensitivity, reaching the peak 30 min after 4-HNE administration (Figure 1B). Therefore, we selected the $60 \mathrm{nmol} / \mathrm{paw}$ dose for the time course study. The 4-HNE hypersensitivity effect persists for $8 \mathrm{~h}$ (Figure 1C).
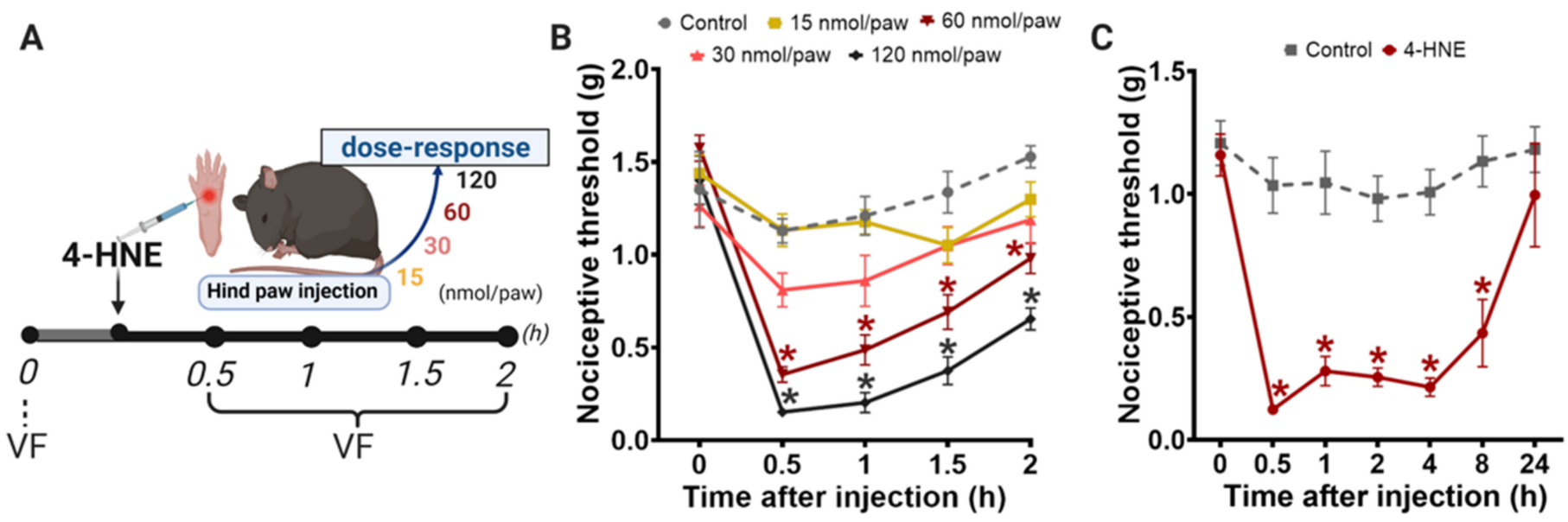

Figure 1. Dose-response curve and time course of 4-HNE-induced mechanical hypersensitivity. (A) Schematic panel of pain threshold assessment by von Frey filament test (VF) and the treatment protocol. (B) 4-HNE was injected intraplantarly (15, 30, 60, and $120 \mathrm{nmol} / \mathrm{paw}$ ) and the nociceptive threshold was assessed by von Frey filaments, by an "up-down" method. (C) Time-course of 4-HNE-induced mechanical hypersensitivity (60 nmol/paw). Error bars represent mean \pm SEM; $n=8$ per condition. ${ }^{*} p<0.05$ when compared with the baseline measure (time 0 ). Two-way analyses of variance (ANOVA) with post-hoc testing by Tukey. The observer was blinded to the experimental conditions.

Next, to characterize the role of PKC $\varepsilon$ in 4-HNE-induced mechanical hypersensitivity, we used a genetic mouse model with decreased PKC $\varepsilon$ expression (Figure 2A). As expected, $\mathrm{PKC} \varepsilon$ protein levels were significantly reduced in plantar tissue from heterozygous $\mathrm{PKC} \varepsilon^{+/-}$mice when compared with WT littermates (Figure 2B). Interestingly, PKC $\varepsilon^{+/-}$ mice showed extended 4-HNE-induced mechanical hypersensitivity when compared with wild-type (Figure 2C,D). These data suggest that PKC $\varepsilon$ contributes to 4-HNE-induced nociception recovery in mice.

To further characterize the role PKCE-ALDH2 axis in 4-HNE-induced nociception, we next used knockin mice carrying the inactivating Lys487 point mutation in ALDH2, identical to the mutation found in Han Chinese [28]; denoted ALDH2*2 [9]. We evaluated the effect of $4-\mathrm{HNE}$ injection in the hind paw of ALDH2*2 and WT mice (Figure 2E). As expected, ALDH 2 protein level was reduced in the paw of ALDH2*2 mice when compared with WT (Figure 2F). The behavioral experiment showed that ALDH2*2 animals display persistent hypersensitivity that lasted $24 \mathrm{~h}$ (Figure 2G). Moreover, consistent with increased hypersensitivity $24 \mathrm{~h}$ after 4 -HNE administration, ALDH2*2 mice present higher 4-HNE adduct levels in their paws when compared with WT (Figure 2H). Overall, our results using genetically modified animals provide evidence that both $\mathrm{PKC} \varepsilon$ and ALDH2 are independent and critical players in counteracting 4-HNE-induced nociception in mice. Next, we tested whether selective pharmacological activation of mitochondrial PKC $\varepsilon$ ALDH2 axis counteracts aldehydic load and improves pain-related behaviors triggered by 4 -HNE. 

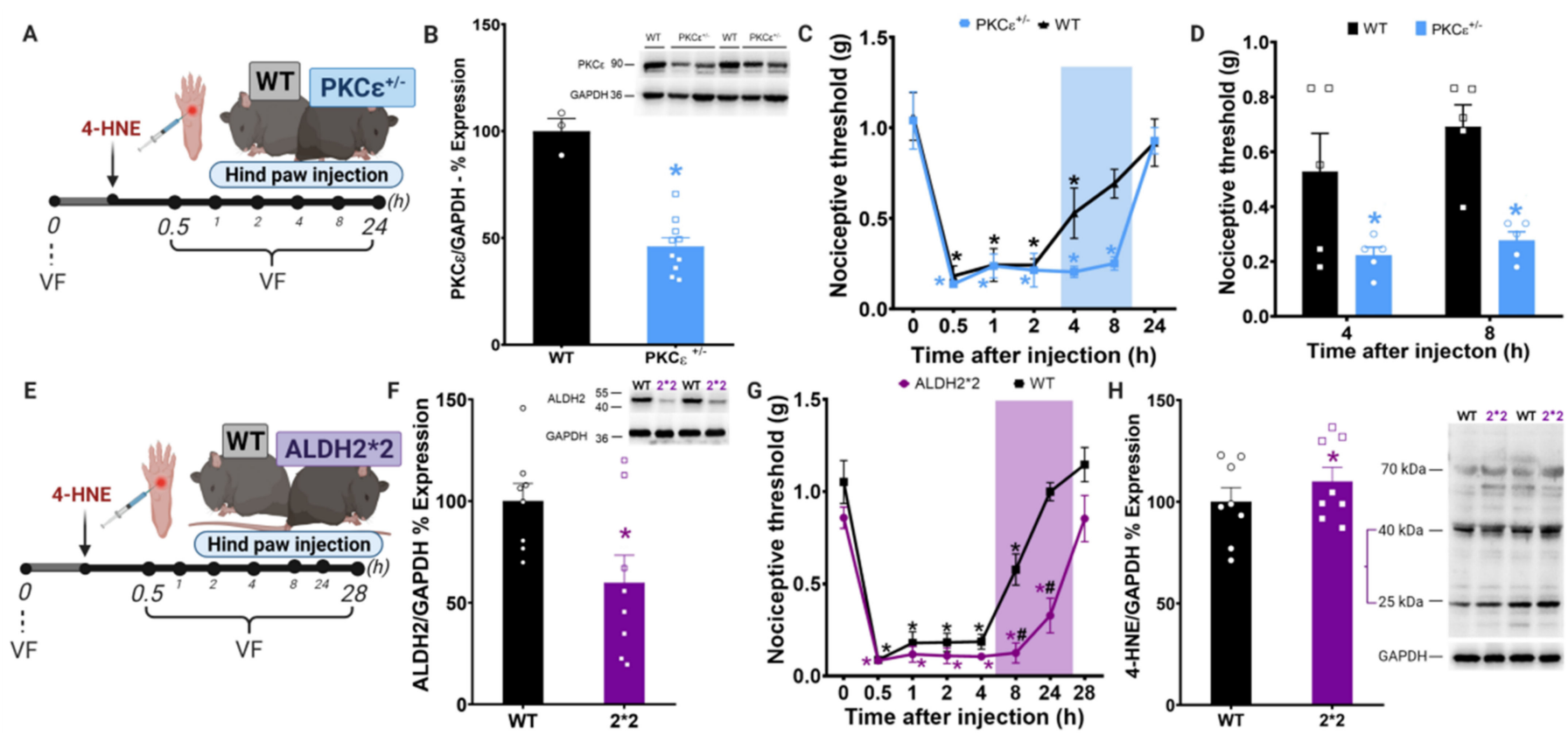

Figure 2. Disruption of $\mathrm{PKC} \mathcal{E}-\mathrm{ALDH} 2$ axis contributes to 4-HNE-induced mechanical hypersensitivity. (A) Schematic panel of drug administration and von Frey filament test (VF) in PKC $\varepsilon^{+/-}$animals. (B) PKC $\varepsilon$ expression in the paw tissue of wild-type and $\mathrm{PKC} \varepsilon^{+/-}$mice. T-test ${ }^{*} p<0.05$ compared to wild type. $n=8 /$ group. (C) Time-course of 4 -HNE-induced mechanical hypersensitivity $(60 \mathrm{nmol} / \mathrm{paw})$ in $\mathrm{PKC} \varepsilon^{+/-}$. Two-way analysis of variance (ANOVA) with post-hoc testing by Tukey * $p<0.05$ compared to baseline. $n=8$ /group. (D) $\mathrm{PKC} \varepsilon^{+/-}$animals have more hypersensitivity when compared to wild-type animals at 4 and $8 \mathrm{~h}$ after 4 -HNE injection. One-way analysis of variance (ANOVA) with post-hoc testing by Tukey. ${ }^{*} p<0.05$ compared to wild-type. $n=8$ /group. (E) Schematic panel of drug administration and von Frey filament test in ALDH2 2 animals (mice with impairment in ALDH2 activity). $n=8$ /group. (F) ALDH2 expression in paw tissues of wild type and ALDH2*2. T-test * $p<0.05$ compared to wild type. $n=8$ /group. (G) Impairment in ALDH2 activity (ALDH2*2) increases the hypersensitivity when compared to wild-type animals at 8 and $24 \mathrm{~h}$ after 4 -HNE injection. Two-way analysis of variance (ANOVA) with post-hoc testing by Tukey * $p<0.05$ compared to baseline, $\# p<0.05$ compared to wild-type. $n=8$ /group. (H) representative western blot and \% change in 4-HNE protein adducts in proteins extracted from paws treated with 4-HNE ( $60 \mathrm{nmol} / \mathrm{paw})$ of wild type and ALDH2*2 mice (GAPDH used as loading control). T-test $* p<0.05$ compared to wild type. $n=8$ /group. All data are means \pm SEM. Pain assessment was carried out by an observer blinded to the experimental conditions.

\subsection{Selective Activation of PKCE in Mitochondria Blocks 4-HNE-Induced Hypersensitivity}

We previously reported that acute administration of $\Psi \varepsilon \mathrm{HSP} 90$, a peptide that increases mitochondrial PKC $\varepsilon$ translocation, induces cardioprotection by favoring PKC $\varepsilon$ phosphorylation/activation of ALDH2 [29,30] (Figure 3A). Here, we used a similar approach to test whether $\Psi \varepsilon$ HSP90-induced mitochondrial PKC $\varepsilon$ translocation, and consequent activation of PKC $\varepsilon$-ALDH2 axis, prevents 4-HNE-induced hypersensitivity in mice (Figure 3B). First, we replicated the literature findings showing that $\Psi \varepsilon$ RACK-induced global activation of $\mathrm{PKC} \varepsilon$ is sufficient to induce hypersensitivity in mice (Figure 3C). Of interest, the administration of $\Psi_{\varepsilon} \mathrm{HSP} 90$ per se did not cause pain in mice (Figure 3C). As expected, $\Psi \varepsilon \mathrm{HSP} 90$ did not neutralize hypersensitivity induced by the global PKC $\varepsilon$ activator, $\Psi$ \&ACK [6,31], when co-administered (Figure 3C). 
A

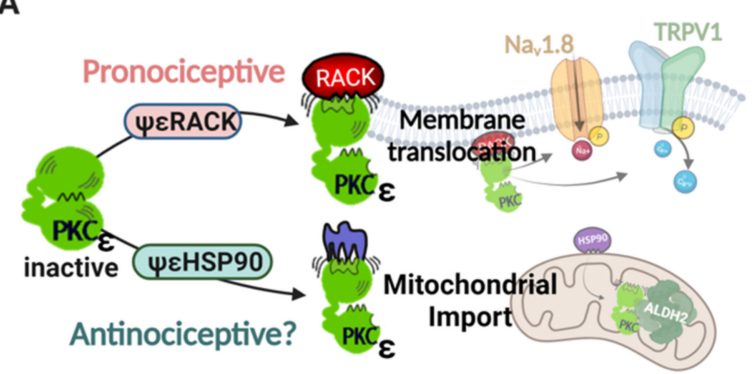

B

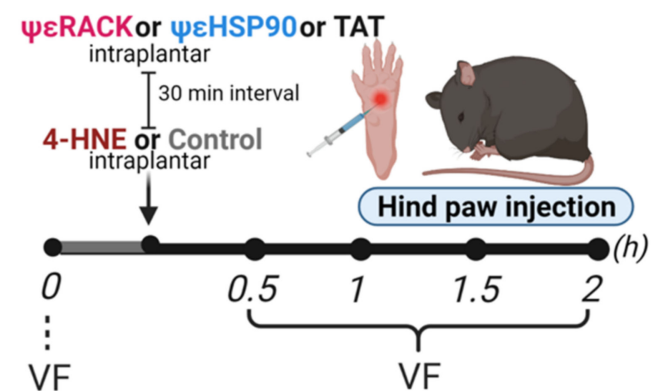

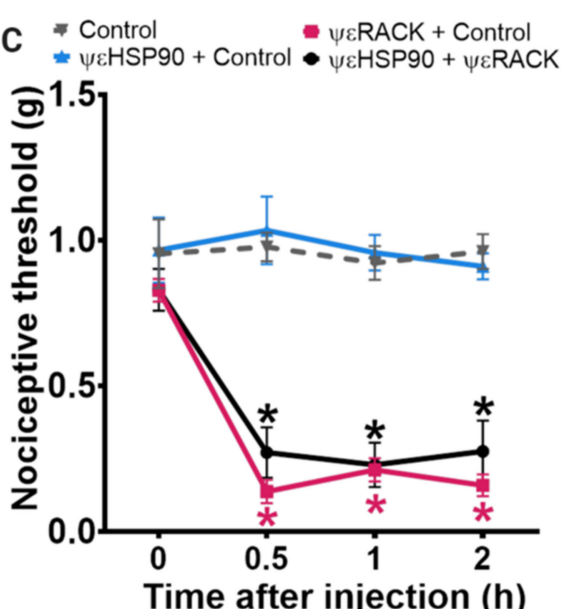
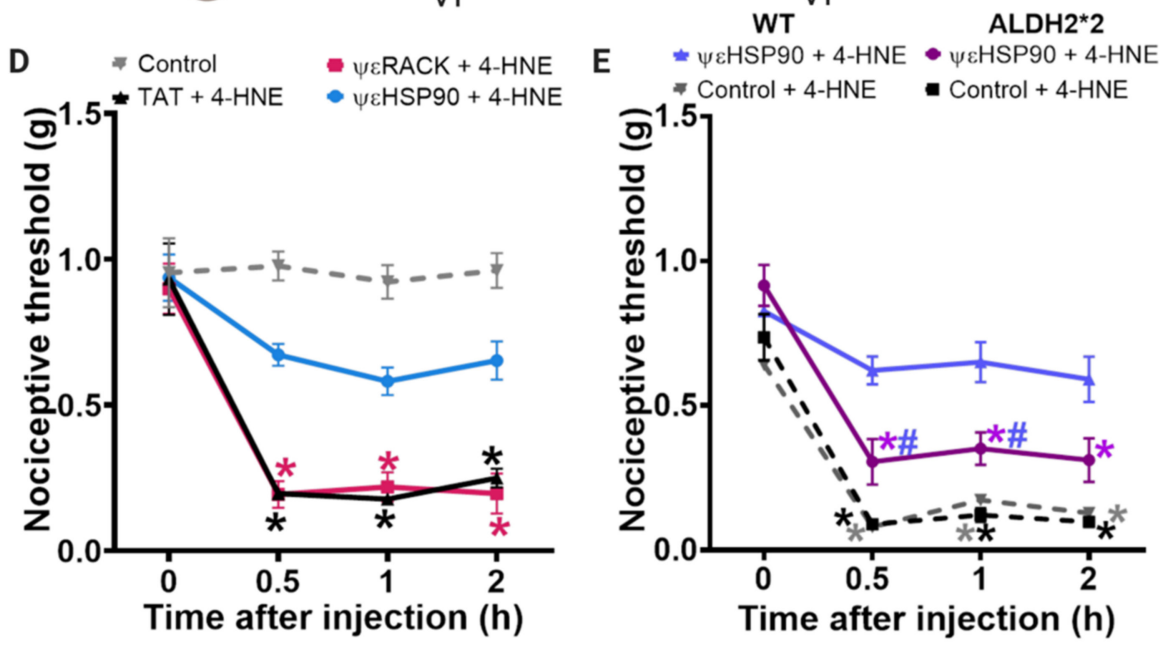

Figure 3. The global activation of PKC $\varepsilon$ is pro-nociceptive and the mitochondrial activation of PKC $\varepsilon$ blocks 4-HNE-induced nociception. (A) Schematic panel showing cytosolic and mitochondrial targets of PKCE. (B) Schematic panel of drug administration and von Frey filament test (VF) in wild type or ALDH2*2 animals (mice with impairment in ALDH2 activity). (C) $\Psi_{\varepsilon H S P 90 ~}(1 \mu \mathrm{g} / \mathrm{paw}), \Psi_{\varepsilon}$ RACK $(1 \mu \mathrm{g} / \mathrm{paw})$ i.pl. were administered $30 \mathrm{~min}$ before the vehicle or $\Psi_{\varepsilon} \mathrm{HSP} 90$ (black line). (D) $\Psi \varepsilon$ HSP90 $(1 \mu \mathrm{g} / \mathrm{paw})$ or TAT $(1 \mu \mathrm{g} / \mathrm{paw})$ were administered $30 \mathrm{~min}$ before the 4 -HNE or vehicle (gray line). (E) WT and ALDH2*2 received $\Psi \varepsilon$ HSP90 or TAT $(1 \mu \mathrm{g} / \mathrm{paw})$. Two-way analyses of variance (ANOVA) with post-hoc testing by Tukey. ${ }^{*} p<0.05$ when compared with the baseline (time 0 ). $\# p<0.05$ when compared to the vehicle group (control). Error bars represent mean \pm SEM; $n=6-8$ per condition. Pain assessment was carried out by an observer blinded to the experimental conditions.

Next, we tested the efficacy of $\Psi_{\varepsilon H S P 90}$ peptide in reducing 4-HNE-induced hypersensitivity. Our findings demonstrated that intraplantar administration of $\Psi \varepsilon \mathrm{HSP} 90$ peptide induces a sustained improvement of nociceptive threshold in mice injected with 4HNE (Figure 3D). However, the pretreatment with the global activator ( $\Psi$ \&ACK) does not prevent 4-HNE-induced hypersensitivity (Figure 3D). To further prove that PKC $\varepsilon$-induced analgesia works through ALDH2 activation, we treated ALDH2*2 deficient mice with $\Psi_{\varepsilon} \mathrm{HSP} 90$ before 4-HNE administration (Figure 3D). Our results showed that genetically modified mice with impaired ALDH2 activity are resistant to $\Psi \varepsilon$ HSP 90 -induced benefits during exogenous 4-HNE-induced hypersensitivity (Figure 3E). These findings suggest that functional ALDH2 is required to mediate PKC $\varepsilon$-induced analgesia under aldehydic load conditions.

To further characterize mitochondrial ALDH2 as a downstream PKC $\varepsilon$ effector, we next used a selective small molecule activator of ALDH2, termed Alda-1 [29], during 4-HNEinduced nociception (Figure 4A). Of interest, administration of Alda- 1 before the insult was sufficient to completely prevent 4-HNE-induced hypersensitivity in mice (Figure 4B); therefore, validating the critical role of ALDH2 in counteracting aldehyde-induced pain. Indeed, we provided evidence that direct activation of ALDH2 can circumvent the requirement of $\mathrm{PKC} \varepsilon$ to reduce pain. 

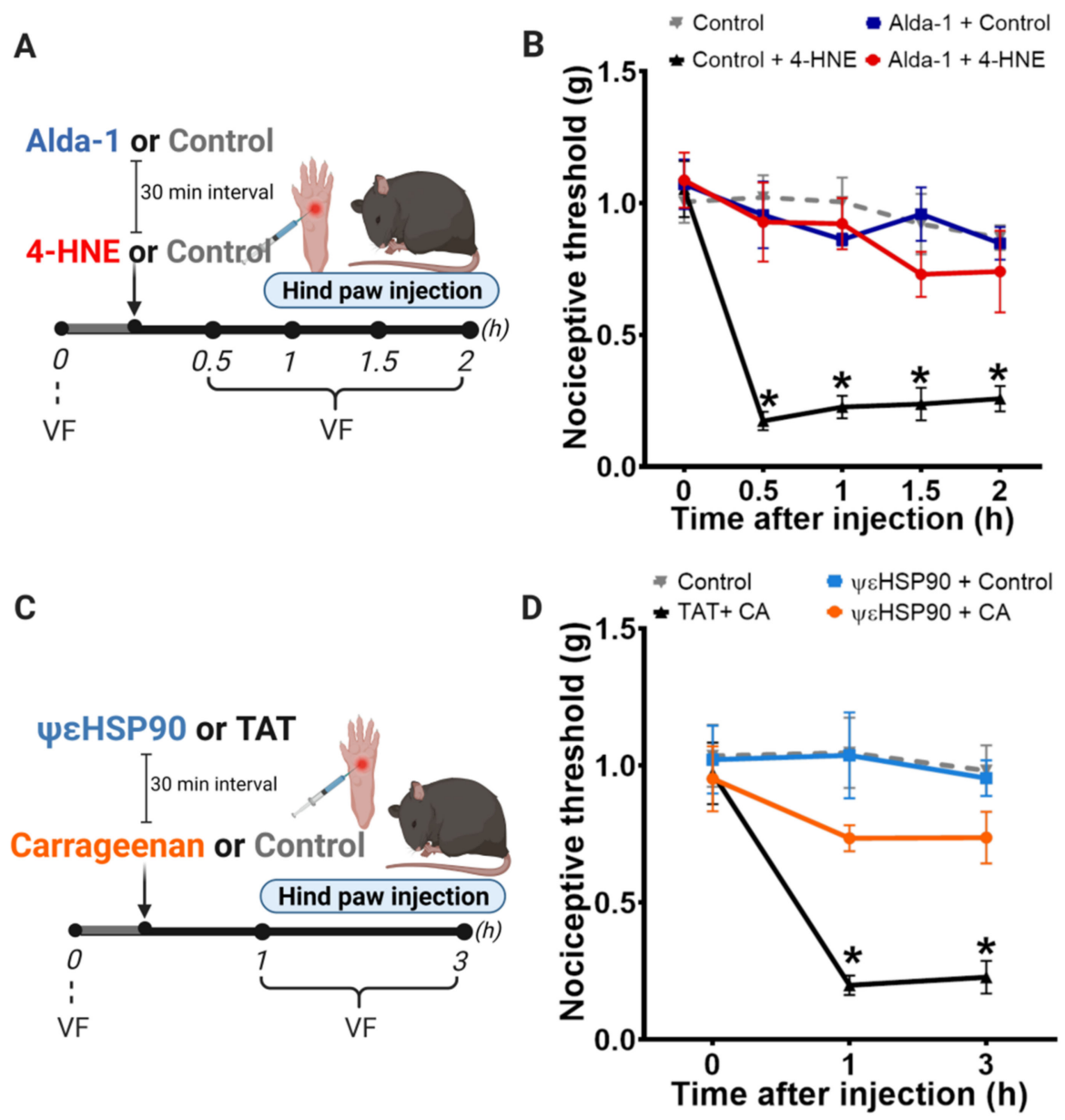

Figure 4. Activation of ALDH2 by Alda-1 prevents 4-HNE-induced nociception and by $\Psi$ \&HSP90 prevents carrageenan-induced nociception. (A) Schematic panel of drug administration and von Frey filament (VF). (B) Wild type animals received Alda-1 $(10 \mathrm{mg} / \mathrm{kg})$ s.c. $30 \mathrm{~min}$ before $4-\mathrm{HNE}(60 \mathrm{nmol} / \mathrm{paw})$ i.pl. (C) Schematic panel of drug administration and von Frey filament (VF) (D) Wild type animals received $\Psi_{\varepsilon}$ HSP90 or TAT $(1 \mu \mathrm{g} / \mathrm{paw})$, i.pl., $30 \mathrm{~min}$ before carrageenan (CA) $\left.(100 \mu \mathrm{g} / \mathrm{paw}) / \mathrm{paw}\right)$ or saline i.pl. Error bars represent mean $\pm \mathrm{SEM} ; n=8$ per condition. Two-way analyses of variance (ANOVA) with post-hoc testing by Tukey. ${ }^{*} p<0.05$ when compared with the baseline (time 0 ). Pain assessment was carried out by an observer blinded to the experimental conditions.

\subsection{Selective Activation of $P K C \varepsilon$ in Mitochondria Prevents Carrageenan-Induced Hypersensitivity}

Next, we asked whether activation of mitochondrial PKC $\varepsilon$-ALDH2 axis blocks mechanical hypersensitivity induced by endogenous production of 4-HNE. Our group previously demonstrated that 4-HNE accumulates in the hind paw and becomes a key mediator in carrageenan-induced mechanical hypersensitivity [9]. To explore the benefits of activating mitochondrial PKC $\varepsilon$-ALDH2 axis during carrageenan-mediated inflammatory pain, we treated WT mice with $\Psi_{\varepsilon} \mathrm{HSP} 90$ before carrageenan injection (Figure $4 \mathrm{C}$ ). As shown in the Figure 4D, $\Psi_{\varepsilon}$ HSP90 blocked carrageenan-induced inflammatory nociception, providing evidence that $\mathrm{PKC} \varepsilon$ activation of ALDH2 is sufficient to prevent inflammatory pain-like behavior.

Mechanistically, 4-HNE triggers nociception, at least in part, by activating TRPA1 receptors [16]. As expected, I-TRPA1 (HC 030031), a selective TRPA1 receptor antagonist, prevented 4-HNE-induced hypersensitivity (Figure 5B). Importantly, the hypersensitive effect of 4-HNE was not a consequence of an inflammatory response, since indomethacin, a non-steroidal anti-inflammatory drug, did not prevent the 4-HNE-induced hypersensitivity (Figure 5C). 
A

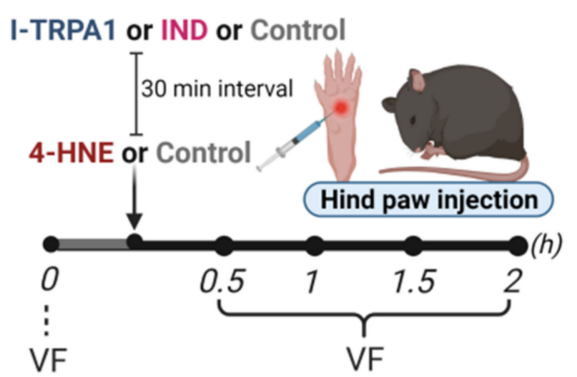

D

$\varepsilon V 1-2$ or TAT

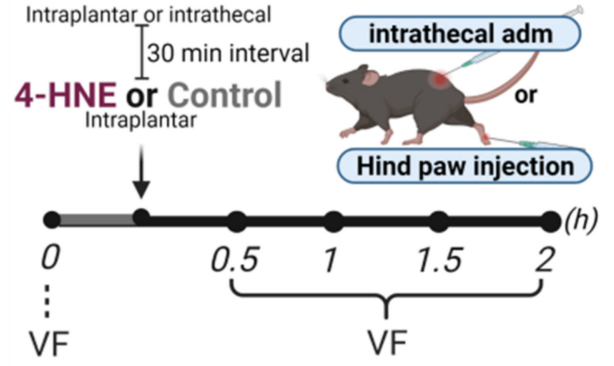

B

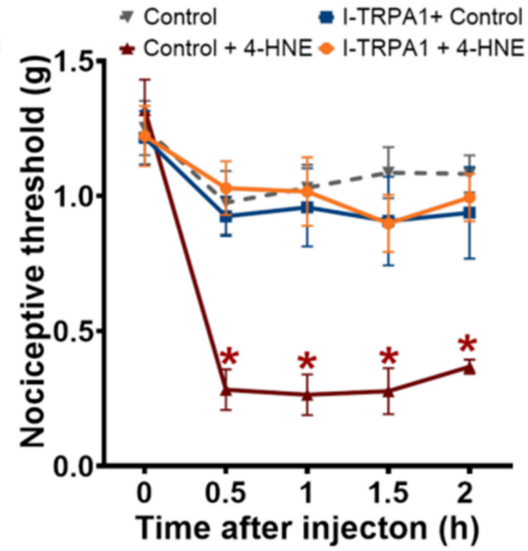

E

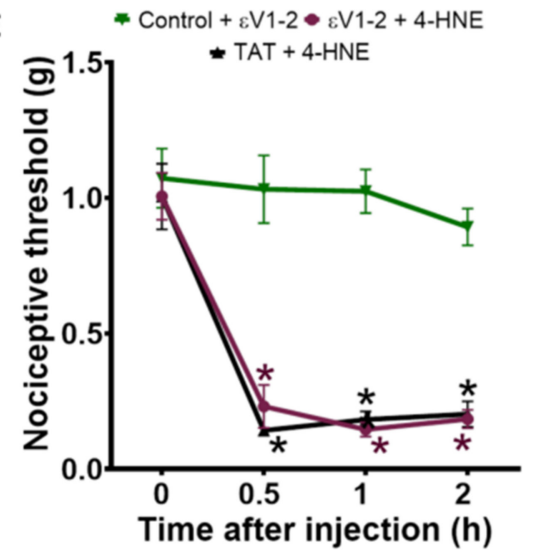

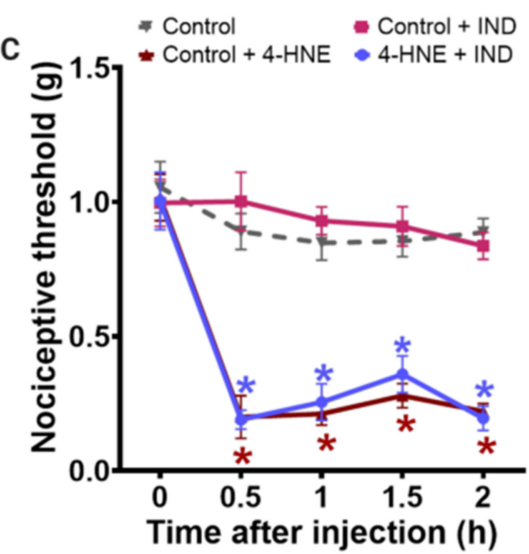

F

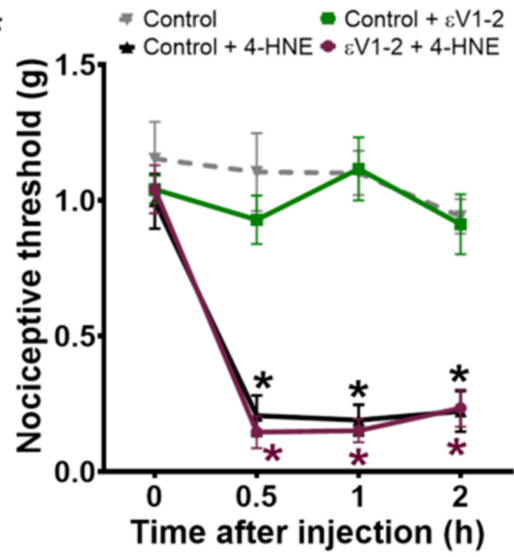

Figure 5. TRPA1 is involved in 4-HNE-induced nociception and the global PKC $\varepsilon$ antagonist does not prevent this hypersensitivity effect. (A) Schematic panel of drug administration and von Frey filament (VF). (B) I-TRPA1 (HC 030031; $300 \mathrm{nmol} / \mathrm{paw})$ or vehicle were administered $30 \mathrm{~min}$ before $4-\mathrm{HNE}(60 \mathrm{nmol} / \mathrm{paw})$. (C) Indomethacin $(10 \mathrm{mg} / \mathrm{kg}$, i.p) or vehicle (i.p) were administered $30 \mathrm{~min}$ before 4-HNE (60 nmol/paw). (D) Schematic panel of drug administration and von Frey filament (VF). (E) $\varepsilon$ V1-2 (1 $\mu \mathrm{g} / \mathrm{paw})$ i.pl. was administered $30 \mathrm{~min}$ before the injection of 4-HNE $(60 \mathrm{nmol} / \mathrm{paw})$ i.pl. (F) $\varepsilon$ V1-2 (1.35 $\mu \mathrm{g} /$ animal) i.t. was administered $15 \mathrm{~min}$ before 4-HNE $(60 \mathrm{nmol} / \mathrm{paw})$. Error bars represent mean $\pm \mathrm{SEM}$; $n=8$ per condition. Two-way analyses of variance (ANOVA) with post-hoc testing by Tukey. ${ }^{*} p<0.05$ when compared with the baseline (time 0 ). Pain assessment was carried out by an observer blinded to the experimental conditions.

Finally, some groups claim that $\mathrm{PKC} \varepsilon$ is highly expressed in sensory neurons and plays an important role in triggering nociception by activating TRPV1 receptors [32,33] and/or Nav1.8 channels [6] in the plasmatic membrane. In fact, PKC $\varepsilon$ inhibitor peptide $(\varepsilon V 1-2)$ prevents hypersensitivity in several rodent models of pain [22,31,34]. However, whether pharmacological PKC $\varepsilon$ inhibition affects 4-HNE-induced hypersensitivity was not determined. To address this question, we assessed the role of peripheral and central PKC $\varepsilon$ inhibition in 4-HNE-induced nociception. For that, we injected $\varepsilon V 1-2$ intraplantarly or intrathecally prior to 4-HNE administration. Our results demonstrated that neither peripheral nor central PKC $\varepsilon$ inhibition affects 4-HNE-induced mechanical hypersensitivity during the first $2 \mathrm{~h}$ after $4-\mathrm{HNE}$ injection in mice (Figure 5E,F), similar to our data observed in $\mathrm{PKC} \varepsilon \mathrm{KO}$ mice.

\section{Discussion}

In this study, using strategies of loss and gain of function, we showed that the PKCEALDH2 axis plays an important role in 4-HNE-induced nociception. Using transgenic mice, we showed that a reduction in PKC $\varepsilon$ or ALDH2 levels strongly compromises the 4-HNE removal and prolongs the nociception. Importantly, selectively activating mitochondrial PKC $\varepsilon$ (with $\Psi_{\varepsilon}$ HSP90) or ALDH2 (with Alda-1) successfully prevented 4-HNE-induced hypersensitivity. Finally, we showed that the treatment with $\Psi \varepsilon \mathrm{HSP} 90$ is sufficient to 
prevent carrageenan-induced nociception, a model in which endogenous 4-HNE accumulates and became a key mediator of nociception. Our study provided evidence that the design of molecules that competitively disrupt a specific protein-protein interaction (kinasechaperone), such as, $\Psi \varepsilon$ HSP90, is a promising approach to develop more feasible drugs that selectively affect only detrimental kinase substrate interactions in pain pathophysiology.

Aldehydes are highly diffusible and reactive agents generated during numerous painful processes. 4-HNE is a relatively stable compound that can travel remarkable distances from the site of synthesis. This aldehyde can reach measurable concentrations in the tissues and in the blood. Its physiological concentration is in the sub micromolar range $(<0.1 \mu \mathrm{M})$, while in oxidative stress, even micromolar levels can be observed [35,36]. Therefore, the concentration of 4-HNE presently used may represent levels compatible with 4-HNE-produced in a pathological condition. 4-HNE has been implicated in tissue damage, dysfunction, and pain associated with neurodegenerative diseases such as multiple sclerosis, cancer, diabetes, endometriosis, among others [11,37]. The mechanisms by which 4-HNE contributes to these pathologies are unknown, however, it is well established that the sustained lipid peroxidation and further accumulation of 4-HNE lead to impaired mitochondrial function, which further contribute to the disease progress. Therefore, understanding the molecular pathways involved in 4-HNE control may be of great importance for treating multiple pain related pathologies.

We showed previously that ALDH2 is a PKC $\varepsilon$ substrate $[10,29]$ and a regulator of acute nociception in rodents. Therefore, we tested the hypothesis that the disruption in PKC $\varepsilon$ ALDH2 axis would aggravate 4-HNE-induced nociception. Our data showed that 4-HNE induces extended hypernociception in both $\mathrm{PKC} \varepsilon$ and $\mathrm{ALDH} 2 * 2$ mice (Figure $2 \mathrm{C}, \mathrm{G}$ ). This effect was followed by 4 -HNE accumulation in paws of ALDH2*2 mice, confirming that ALDH2 is essential for 4-HNE detoxification. We have previously showed that ALDH2*2 are more sensitive to carrageenan, acetaldehyde and formalin-induced nociceptive behavior than wild-type mice [9]. However, whether $\mathrm{PKC} \varepsilon^{+/-}$mice also accumulate 4-HNE as a consequence of ALDH2 impairment remains to be investigated.

Previous studies demonstrated that full knockout PKC $\varepsilon$ mice show decreased epinephrineinduced hyperalgesia [5]. However, to our knowledge, there are no studies evaluating endogenous aldehydes-mediated nociception, for example, induced by carrageenan, in full knockout PKC $\varepsilon$ mice. Therefore, further studies are necessary to clarify the role of PKC $\varepsilon-A L D H 2$ axis in those models. A limitation of our study is our inability to breed full knockout (homozygotic) mice in our laboratory. However, heterozygous may have advantages since the remaining protein expression lowers the chance of unexpected compensatory mechanisms activation [38].

Mitochondrial translocation of PKC $\varepsilon$ is mediated by HSP90, which permits mitochondrial import of PKC $\varepsilon$ by the import receptor Tom20 [39]. $\Psi \varepsilon$ HSP90 is a 7-amino acid peptide activator of $\mathrm{PKC} \varepsilon$, derived from an HSP90 homologous sequence located in the $\mathrm{C} 2$ domain of PKC $\varepsilon$. Importantly, $\Psi_{\varepsilon} \mathrm{HSP} 90$ activates ALDH2 without inducing PKC $\varepsilon$ translocation to the plasma membrane [30]. This was confirmed by our behavior data showing that, differently from the global activator $\Psi \varepsilon R A C K, \Psi \varepsilon H S P 90$ does not induce hypernociception when injected alone. Then, we asked whether $\Psi \varepsilon$ HSP90 would have a beneficial effect in 4-HNE-induced mechanical hypersensitivity. Interestingly, our results demonstrated that this peptide significantly prevents 4-HNE-induced mechanical hypersensitivity. Furthermore, to prove that PKC $\varepsilon$-induced analgesia works through ALDH2 activation, we showed that $\Psi \varepsilon \mathrm{HSP} 90$ did not prevent the mechanical hypersensitivity in $\mathrm{ALDH} 2 * 2$ mice. Because $\mathrm{ALDH}^{*} 2$ variant induces a structural deficit in both the

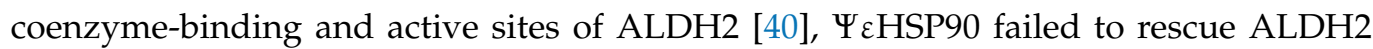
activity, losing its analgesic effect. These data confirm again that PKC $\varepsilon$-induced analgesia requires a functional ALDH2 to remove toxic aldehydes. Importantly, we also showed that the ALDH2 activation with Alda-1 is sufficient to prevent 4-HNE-induced nociception. This is in agreement with the previously report that Alda-1 administration induces analgesia in multiple pain models, associated with a significant reduction of 4-HNE adducts [9,12,13]. 
Therefore, with this study we confirm that 4-HNE clearance is sufficient to induce analgesia even by exogenous administration.

Aiming to translate the $\Psi \varepsilon \mathrm{HSP} 90$ analgesic effect into a broadly inflammatory pain model, we tested the peptide in carrageenan-induced mechanical hypersensitivity. $\Psi \varepsilon H S P 90$ was effective in preventing inflammatory pain-like behaviors, confirming our hypothesis that $\mathrm{PKC} \varepsilon$ activation may have a protective effect by controlling the mitochondrial ALDH2 activity. As mentioned before, the PKC $\varepsilon$ global activation in sensory neurons is pro-nociceptive by depolarizing and/or sensitizing afferent neurons following inflammatory insult [41-43]. Here, we showed, for the first time, that PKC $\varepsilon$ may have a protective effect through the ALDH2 axis. We also showed that the $\varepsilon$ V1-2 peptide (global PKC $\varepsilon$ antagonist) did not interfere with 4-HNE mechanical hypersensitivity when administered either peripherally or intrathecally. Importantly, $\varepsilon V 1-2$ blocks PKC $\varepsilon$ translocation and reduces hyperalgesia in a variety of inflammatory and neuropathic pain rodent models [22,31,34]. However, considering that $\mathrm{PKC} \varepsilon$ activates different signaling pathways simultaneously, the global $\mathrm{PKC} \varepsilon$ inhibition may compromise essential downstream pathways, such as, ALDH2-induced 4-HNE removal from the injured tissue.

Finally, we demonstrated that TRPA1 activation mediates 4-HNE-induced mechanical hypersensitivity. Trevisani and colleagues [16] have demonstrated that the dose of 4-HNE presently used, $60 \mathrm{nmol}$ per paw, induces spontaneous nocifensive behavior in mice, such as paw licking and lifting, immediately after administration and this effect is mediated by TRPA1 receptors. Our study demonstrated that $60 \mathrm{nmol}$ of 4-HNE lowers the mechanical threshold for $>8 \mathrm{~h}$ and that Alda-1 prevented 4-HNE-induced mechanical hypersensitivity. Therefore, it is very likely that besides activating TRPA-1 receptors, the exogenous 4HNE triggers endogenous 4-HNE formation, which is prevented by ALDH2 activation with Alda-1. Further studies are necessary to investigate this hypothesis; for example, Schwann cells expressing TRPA1 receptors recruit macrophages upon activation, triggering oxidative stress and 4-HNE formation [44]. Therefore, it is possible that Alda-1 would fail to block 4-HNE-induced nociception immediately after the aldehyde injection, for example 5-20 min afterwards, the time point that 4-HNE may directly induce nociception by activating TRPA1 receptors. Also, 4-HNE itself may inactivate ALDH2, thus limiting its own removal. Therefore, the endogenous 4-HNE release possibly contributes to the pain-like behavior detected in longer time points such as $4-8 \mathrm{~h}$ in the wild type mice and $24 \mathrm{~h}$ in the $\mathrm{ALDH} 2 * 2$ mice.

In our study, we did not investigate which are the main cells expressing PKC $\varepsilon$-ALDH2 in the paw tissue, however, mitochondria are widely transported along axons and dendrites to the regions of higher energy demands, such as injured tissue. However, although neurons express ALDH2, there is recent evidence showing that spinal astrocytic ALDH2, but not neuronal, mediates alcohol-induced analgesia via acetate-GABA metabolic pathway [45]. Therefore, the ALDH2 functions go beyond aldehyde detoxification in the pathophysiology of pain.

Regardless of the signaling pathways involved in PKC $\varepsilon$ activity in the nociceptors, designing therapeutics limiting reactive aldehyde production may provide treatments particularly helpful as a pre-treatment when pain is expected, such as post-surgeries.

\section{Conclusions}

In conclusion, our results demonstrate that ALDH2 is an important PKC $\varepsilon$ substrate in attenuating 4-HNE hypersensitive effects. Targeting mitochondrial PKC $\varepsilon$ may become a good strategy to mitigate inflammatory pain.

Author Contributions: V.O.Z. conceived and designed this study. V.O.Z. and J.C.B.F. wrote the manuscript with input from G.R.B., C.-H.C., D.M.-R., B.B.M., N.G.H. and Q.A.A. B.B.M. performed the behavioral experiments. N.G.H. performed the Western blot experiments. B.B.M., N.G.H., Q.A.A. and V.O.Z. analyzed the data. All authors have read and agreed to the published version of the manuscript. 
Funding: This research was funded by Fundação de Amparo à Pesquisa do Estado de São Paulo, Brazil (FAPESP, grants numbers 2017/16071-5, 2018/19332-7 and 2013/07467-1-CETICs program); Conselho Nacional de Desenvolvimento Científico e Tecnológico (CNPq) grant number 429221/2018-5. BBM and NGH received a fellowship from Coordenação de Aperfeiçoamento de Pessoal de Nível Superior-Brasil (CAPES)—Finance Code 001. QAA received FAPESP fellowship (2020/04998-0). The work was also supported by NIAA11147 NIH grant to DMR.

Institutional Review Board Statement: The study was conducted according to the guidelines Ethics Committee on the Use of Experimental Animals at the Butantan Institute (protocol \# 4239090318).

Informed Consent Statement: Not applicable.

Acknowledgments: We would like to thank Juliane Campos and Rudá P. Albuquerque for the technical support with genotyping and Flavia Lopes for the intrathecal injections. Schematic images created with BioRender.com.

Conflicts of Interest: V.O.Z., C.-H.C. and D.M.-R. are named inventors of patents related to Alda-1.

\section{References}

1. Goldberg, D.S.; McGee, S.J. Pain as a Global Public Health Priority. BMC Public Health 2011, 11, 770. [CrossRef] [PubMed]

2. Holmes, D. The pain drain. Nature 2016, 535, S2-S3. [CrossRef] [PubMed]

3. Disatnik, M.H.; Jones, S.N.; Mochly-Rosen, D. Stimulus-dependent subcellular localization of activated protein kinase C; a study with acidic fibroblast growth factor and transforming growth factor- $\beta 1$ in cardiac myocytes. J. Mol. Cell. Cardiol. 1995, 27 , 2473-2481. [CrossRef]

4. Cesare, P.; Dekker, L.V.; Sardini, A.; Parker, P.J.; Mcnaughton, P.A. Specific Involvement of PKC- $\varepsilon$ in Sensitization of the Neuronal Response to Painful Heat plaining the lowering of the threshold for heat pain that. Neuron 1999, 23, 617-624. [CrossRef]

5. Khasar, S.G.; Lin, Y.-H.; Martin, A.; Dadgar, J.; McMahon, T.; Wang, D.; Hundle, B.; Aley, K.; Isenberg, W.; McCarter, G.; et al. A novel nociceptor signaling pathway revealed in protein kinase c $\varepsilon$ mutant mice. Neuron 1999, 24, 253-260. [CrossRef]

6. Wu, D.-F.; Chandra, D.; McMahon, T.; Wang, D.; Dadgar, J.; Kharazia, V.N.; Liang, Y.-J.; Waxman, S.G.; Dib-Hajj, S.D.; Messing, R. $\mathrm{PKC} \varepsilon$ phosphorylation of the sodium channel Na V1.8 increases channel function and produces mechanical hyperalgesia in mice. J. Clin. Investig. 2012, 122, 1306-1315. [CrossRef]

7. Cousins, M.J.; Pickthorn, K.; Huang, S.; Critchley, L.; Bell, G. The Safety and Efficacy of KAI-1678- An Inhibitor of Epsilon Protein Kinase C ( $\varepsilon$ PKC)-Versus Lidocaine and Placebo for the Treatment of Postherpetic Neuralgia: A Crossover Study Design. Pain Med. 2013, 14, 533-540. [CrossRef] [PubMed]

8. Moodie, J.E.; Bisley, E.J.; Huang, S.; Pickthorn, K.; Bell, G. A Single-Center, Randomized, Double-Blind, Active, and PlaceboControlled Study of KAI-1678, a Novel PKC-Epsilon Inhibitor, in the Treatment of Acute Postoperative Orthopedic Pain. Pain Med. 2013, 916-924. [CrossRef]

9. Zambelli, V.O.; Gross, E.R.; Chen, C.H.; Gutierrez, V.P.; Cury, Y.; Mochly-Rosen, D. Aldehyde dehydrogenase-2 regulates nociception in rodent models of acute inflammatory pain. Sci. Transl. Med. 2014, 6, 251ra118. [CrossRef]

10. Chen, C.H.; Ferreira, J.C.B.; Gross, E.R.; Mochly-Rosen, D. Targeting aldehyde dehydrogenase 2: New therapeutic opportunities. Physiol. Rev. 2014, 94, 1-34. [CrossRef]

11. Dalleau, S.; Baradat, M.; Guéraud, F.; Huc, L. Cell death and diseases related to oxidative stress:4-hydroxynonenal (HNE) in the balance. Cell Death Differ. 2013, 20, 1615-1630. [CrossRef] [PubMed]

12. McAllister, S.L.; Sinharoy, P.; Vasu, M.; Gross, E.R. Aberrant reactive aldehyde detoxification by aldehyde dehydrogenase-2 influences endometriosis development and pain-associated behaviors. Pain 2021, 162, 71-83. [CrossRef]

13. Khan, M.; Qiao, F.; Kumar, P.; Islam, S.M.T.; Singh, A.K.; Won, J.; Singh, I. Neuroprotective effects of Alda-1 mitigate spinal cord injury in mice: Involvement of Alda-1-induced ALDH2 activation-mediated suppression of reactive aldehyde mechanisms. Neural Regen. Res. 2022, 17, 185-193. [CrossRef] [PubMed]

14. Ritter, C.; Dalenogare, D.P.; de Almeida, A.S.; Pereira, V.L.; Pereira, G.C.; Fialho, M.F.P.; Lückemeyer, D.D.; Antoniazzi, C.; Kudsi, S.Q.; Ferreira, J.; et al. Nociception in a Progressive Multiple Sclerosis Model in Mice Is Dependent on Spinal TRPA1 Channel Activation. Mol. Neurobiol. 2020, 57, 2420-2435. [CrossRef] [PubMed]

15. Marone, I.M.; De Logu, F.; Nassini, R.; Goncalves, M.D.C.; Benemei, S.; Ferreira, J.; Jain, P.; Puma, S.L.; Bunnett, N.W.; Geppetti, P.; et al. TRPA1/NOX in the soma of trigeminal ganglion neurons mediates migraine-related pain of glyceryl trinitrate in mice. Brain 2018, 141, 2312-2328. [CrossRef]

16. Trevisani, M.; Siemens, J.; Materazzi, S.; Bautista, D.M.; Nassini, R.; Campi, B.; Imamachi, N.; Andre, E.; Patacchini, R.; Cottrell, G.S.; et al. 4-Hydroxynonenal, an endogenous aldehyde, causes pain and neurogenic inflammation through activation of the irritant receptor TRPA1. Anticancer Res. 2007, 104, 13519-13524. [CrossRef]

17. Dalle-Donne, I.; Aldini, G.; Carini, M.; Colombo, R.; Rossi, R.; Milzani, A. Protein carbonylation, cellular dysfunction, and disease progression. J. Cell Mol. Med. 2006, 10, 389-406. [CrossRef]

18. Castrillo, A.; Pennington, D.J.; Otto, F.; Parker, P.J.; Owen, M.J.; Boscá, L. Protein kinase C $\varepsilon$ is required for macrophage activation and defense against bacterial infection. J. Exp. Med. 2001, 194, 1231-1242. [CrossRef] 
19. da Costa, D.S.M.; Meotti, F.C.; Andrade, E.L.; Leal, P.C.; Motta, E.M.; Emerson Marcelo Motta, J.B.C. The involvement of the transient receptor potential A1 (TRPA1) in the maintenance of mechanical and cold hyperalgesia in persistent inflammation. Pain 2010, 148, 431-437. [CrossRef]

20. Trevisan, G.; Hoffmeisterc, C.; Rossatoa, M.F.; Oliveira, S.M.; Silva, M.A.; Silva, C.R.; Fusi, C.; Tonello, R.; Minocci, D.; Guerra, G.P. TRPA1 receptor stimulation by hydrogen peroxide is critical to triggerhyperalgesia and inflammation in a model of acute gout. Free Radic. Biol. Med. 2014, 72, 200-209. [CrossRef]

21. Sant'Anna, M.; Kusuda, R.; Bozzo, T.A.; Bassi, G.S.; Alves-Filho, J.C.; Cunha, F.Q.; Ferreira, S.H.; Souza, G.R.; Cunha, T. Medial plantar nerve ligation as a novel model of neuropathic pain in mice: Pharmacological and molecular characterization. Sci. Rep. 2016, 6, 26955. [CrossRef]

22. Sweitzer, S.; Wong, S. Protein Kinase C $€$ and $\gamma$ Involvement in Formalin-Induced Nociception in Neonatal Rats. J. Pharmacol. Exp. Ther. 2004, 309, 616-625. [CrossRef] [PubMed]

23. He, Y.; Wang, Z.J. Nociceptor beta II, delta, and epsilon isoforms of PKC differentially mediate paclitaxel-induced spontaneous and evoked pain. J. Neurosci. 2015, 35, 4614-4625. [CrossRef]

24. Joseph, E.K.; Reichling, D.B.; Levine, J.D. Shared Mechanisms for Opioid Tolerance and a Transition to Chronic Pain. J. Neurosci. 2010, 30, 4660-4666. [CrossRef]

25. Sun, X.; Budas, G.R.; Xu, L.; Barreto, G.E.; Mochly-Rosen, D.; Sun, X.; Budas, G.R.; Xu, L.; Barreto, G.E.; Daria Mochly-Rosen, R.G.G. Selective activation of protein kinase $C \in$ in mitochondria is neuroprotective in vitro and reduces focal ischemic brain injury in mice. J. Neurosci. Res. 2013, 91, 799-807. [CrossRef]

26. Chaplan, S.R.; Bach, F.W.; Pogrel, J.W.; Chung, J.M.; Yaksh, T.L. Quantitative assessment of tactile allodynia in the rat paw. J. Neurosci. Methods 1994, 53, 55-63. [CrossRef]

27. Dalenogare, D.P.; Theisen, M.C.; Peres, D.S.; Fialho, M.F.P.; Lückemeyer, D.D.; Antoniazzi, C.T.d.D.; Kudsi, S.Q.; Ferreira, M.D.A.; Ritter, C.D.S.; Ferreira, J.; et al. TRPA1 activation mediates nociception behaviors in a mouse model of relapsing-remitting experimental autoimmune encephalomyelitis. Exp. Neurol. 2020, 328, 113241. [CrossRef] [PubMed]

28. Brooks, P.J.; Enoch, M.; Goldman, D.; Li, T.; Yokoyama, A. The Alcohol Flushing Response: An Unrecognized Risk Factor for Esophageal Cancer from Alcohol Consumption. PLoS Med. 2009, 6, 258-263. [CrossRef]

29. Chen, C.-H.; Budas, G.R.; Churchill, E.N.; Disatnik, M.-H.; Hurley, T.D.; Mochly-Rosen, D. Activation of aldehyde dehydrogenase2 reduces ischemic damage to the heart. Supporting Online Mater. Sci. 2008, 321, 1493-1495. [CrossRef] [PubMed]

30. Budas, G.R.; Churchill, E.N.; Disatnik, M.H.; Sun, L.; Mochly-Rosen, D. Mitochondrial import of PKC is mediated by HSP90: A role in cardioprotection from ischaemia and reperfusion injury. Cardiovasc. Res. 2010, 88, 83-92. [CrossRef]

31. Parada, C.A.; Yeh, J.J.; Reichling, D.B.; Levine, J.D. Transient attenuation of protein kinase C $\varepsilon$ can terminate a chronic hyperalgesic state in the rat. Neuroscience 2003, 120, 219-226. [CrossRef]

32. Numazaki, M.; Tominaga, T.; Toyooka, H.; Tominaga, M. Direct phosphorylation of capsaicin receptor VR1 by protein kinase C $\varepsilon$ and identification of two target serine residues. J. Biol. Chem. 2002, 277, 13375-13378. [CrossRef]

33. Srinivasan, R.; Wolfe, D.; Goss, J.; Watkins, S.; de Groat, W.C.; Sculptoreanu, A.; Glorioso, J.C. Protein kinase C epsilon contributes to basal and sensitizing responses of TRPV1 to capsaicin in rat dorsal root ganglion neurons. Eur. J. Neurosci. 2008, 28, 1241-1254. [CrossRef] [PubMed]

34. Sachs, D.; Villarreal, C.; Cunha, F.; Parada, C.; Ferreira, S. The role of PKA and PKCe pathways in prostaglandin E2-mediated hypernociception. Br. J. Pharmacol. 2009, 156, 826-834. [CrossRef] [PubMed]

35. Esterbauer, H.; Schaur, R.J.; Zollner, H. Chemistry and biochemistry of 4-hydroxynonenal, malonaldehyde and related aldehydes. Free Radic. Biol. Med. 1991, 11, 81-128. [CrossRef]

36. Strohmaier, H.; Highofer-Szalkay, H.; Schaur, R.J. Detection of 4-hydroxynonenal (HNE) as a physiological component in human plasma. J. Lipid Mediat. Cell Signal. 1995, 11, 51-61. [CrossRef]

37. Zhong, H.; Yin, H. Role of lipid peroxidation derived 4-hydroxynonenal (4-HNE) in cancer: Focusing on mitochondria. Redox Biol. 2015, 4, 193-199. [CrossRef] [PubMed]

38. El-Brolosy, M.A.; Stainier, D.Y.R. Genetic compensation: A phenomenon in search of mechanisms. PLoS Genet. 2017, 13, 1-17. [CrossRef] [PubMed]

39. Neupert, W.; Herrmann, J.M. Translocation of proteins into mitochondria. Annu. Rev. Biochem. 2007, 76, 723-749. [CrossRef] [PubMed]

40. Perez-Miller, S.; Younus, H.; Vanam, R.; Chen, C.; Mochly-Rosen, D.; Hurley, T.D. Alda-1 is an agonist and chemical chaperone for the common human aldehyde dehydrogenase 2 variant. Nat. Struct Mol. Biol. 2010, 17, 159-164. [CrossRef]

41. Dray, A.; Bettaney, J.; Forster, P.; Perkins, M.N. Bradykinin-induced stimulation of afferent fibres is mediated through protein kinase C. Neurosci. Lett. 1988, 91, 301-307. [CrossRef]

42. Rang, H.P.; Ritchie, J.M. Depolarization of Nonmyelinated Fibers of the Rat Vagus Nerve Produced by Activation of Protein Kinase C. J. Neurosci. 1988, 8, 2606-2617. [CrossRef] [PubMed]

43. Mefllinger, K.; Schmidt, R.F. The effects of phorbol ester on slowly conducting afferents of the cat's knee joint. Exp. Brain Res. 1993, 92, 391-398. 
44. De Logu, F.; De Prá, S.D.-T.; Antoniazzi, C.T.D.D.; Kudsi, S.Q.; Ferro, P.R.; Landini, L.; Rigo, F.K.; Silveira, G.D.B.; Silveira, P.C.L.; Oliveira, S.M.; et al. Macrophages and Schwann cell TRPA1 mediate chronic allodynia in a mouse model of complex regional pain syndrome type I. Brain Behav. Immun. 2020, 88, 535-546. [CrossRef] [PubMed]

45. Jin, S.; Cinar, R.; Hu, X.; Lin, Y.; Luo, G.; Lovinger, D.M. Spinal astrocyte aldehyde dehydrogenase-2 mediates ethanol metabolism and analgesia in mice. Br. J. Anaesth. 2021, 1-14. [CrossRef] [PubMed] 